\title{
Accelerating educational change
}

\author{
Dennis Shirley ${ }^{1}$
}

Published online: 29 July 2017

(C) Springer Science+Business Media B.V. 2017

We live in an age of relentless accelerations (McNeill \& Engelke 2014). The combined forces of technology, globalization, and global warming are catalyzing changes in schools and societies wherever they may be found (Friedman 2016). While many of these changes can be applauded-such as greater access to information via the Internet, increased life expectancy across the continents, and a wealth of new opportunities for cross-cultural dialogue and exchange-these same blessings also have a dark side. Greater access to information brings with it greater access to misinformation as well. Increased longevity means greater budgetary allocations for the elderly and more of a financial burden on younger generations. Cross-cultural dialogue and exchange, which sound so benevolent, can result in acrimonious misunderstandings and worse.

Educational change stands in the midst of these transformations. Should schools abandon time-tested curricula in favor of teaching children computer coding, financial literacy, and group identity? Should schools encourage students to use Facebook, Twitter, and Snapchat as instructional tools-or should they forbid them because they serve as such seductive distractions from traditional and demanding disciplines like physics, chemistry, and foreign languages?

These are complex matters about which professionals will disagree. These topics are inserting themselves increasingly insistently not only into the faculty work room or the research seminar, but also into the everyday, prosaic lives of schools. How much technology is appropriate in the kindergarten classroom? Are standardized tests appropriate ways to measure the abilities of students to solve complex environmental problems? Like it or not, questions like these are facing educators across the globe. The public, used to instant responses on the Internet, seeks reassurance that a rising generation will be prepared for the challenges that await it.

Dennis Shirley

dennis.shirley@bc.edu

1 Lynch School of Education, Boston College, Chestnut Hill, MA, USA 
The Journal of Educational Change exists to guide educators' decision making on the pressing issues facing schools today. But how well is the Journal serving this purpose? To answer this question, a research team comprising Juan GarciaHuidobro, Allison Nannemann, Chris Bacon, and Katherine Thompson undertook a comprehensive literature review of the Journal from 2000 to 2014. Their findings are presented in the first article in this issue of the Journal. By studying citation counts, they identified 5 distinct periods in the Journal's history, spanning from a first one of "assumed universality in scaling educational change" (2000-2002) to the most recent phase of "emergent internationalization and empiricism" (2012-2014).

The research findings and their interpretation provide a veritable tour de force of how the field of educational change has evolved over time through the lens of the Journal. There are fascinating paradoxes and tensions at work here. First, even though the Journal aspires to be international and sensitive to context, its highest level of citation counts occurred in its first phase, of what the authors describe as "assumed universality of scaling educational change." Such a framing of educational change has been discredited in recent years, with the most decimating critique being authored by Richard Elmore, who originally launched the importance of "scale" in his oft-cited article, "Getting to Scale with Good Educational Practice" (1996). In his recent article entitled "Getting to Scale ... It Seemed Like a Good Idea at the Time" in the Journal of Educational Change, Elmore (2016, 529-530) changed course and rejected the premise of "getting to scale" as one of "unthinkable presumptuousness and naiveté" because it was predicated upon an "irresponsibly simplistic and schematic view of human learning and development." Elmore (531) further argued that "every effort at reform is heavily influenced by the contexts, micro and macro, in which it exists. In the face of this understanding, the idea of 'scale' seems either very superficial or downright wrong."

Second, citations in the Journal have very much been dependent upon broader transformations in the field of educational change. Citations declined in a second phase of "emphasizing equity and context," which is perhaps understandable because the articles in this time were more granular and less invested in big ideas that could be transported elsewhere. Citations then picked up again in a third period of "the rise of PISA and the convergence of evidence" as scholars used data from the Program of International Student Assessment (PISA) of the Organization for Economic Cooperation and Development (OECD) to make new claims about the importance of educational professionalism for school improvement. Unfortunately, this evidentiary base has been largely ignored in many of the countries that the authors describe as the "Anglosphere," most notably in the United States and England, but also in parts of Australia and Canada. This then led to a fourth phase of "Reflection and Anglo-American Pessimism," with numerous articles criticizing the combination of market-based reforms and standardized testing that have become prevalent in the Anglosphere recent years.

Which way forward, then, for the Journal of Educational Change and the field in general? In its fifth phase of "emergent internationalization and empiricism," which can be extended to the present day, the Journal has endeavored to become truly international in scope. In an age of increased global interdependence, with 
migratory patterns and new technologies throwing the world's peoples into constant interaction with one another, the Journal now seeks submissions that examine trends across countries and that extend their evidentiary base beyond the Anglosphere. Given the magnitude of contemporary social and political injustices, the Journal is especially interested in articles that address topics regarding equity and inclusion, both within and across countries. Theory-building that transcends parochial national boundaries and speaks to the global nature of the Journal's diverse audience is imperative for this current phase.

These concerns are illustrated in the next four articles of this issue of the Journal. In "Evaluation and Decentralized Governance: Examples of Inspection in Polycentric Education Systems," M.C.M. Ehren and five colleagues for the Institute of Education in London explore school inspection systems in England, Northern Ireland, and the Netherlands. Each school system has sought to create new structures that move beyond the prior "monocentric" forms of bureaucratic organization into more flexible, networked, and "polycentric" forms of governance. These have entailed working with private and non-profit providers of services to uplift teaching and learning. It follows that inspection systems should now go beyond accountability for an individual school to inspection of the effectiveness of their broader polycentric networks.

As the authors demonstrate, however, this has not occurred. In the English case of Multi-Academy Trusts and in the Dutch case of networked regional school authorities organized by the Ministry of Education, Culture, and Science, inspections have remained resolutely focused upon the single school with a hierarchical inspectorate system fully intact. In Northern Ireland, a model of "Area Learning Communities" that adjusted to polycentric networks evolved briefly but recently has been abandoned in favor of returning to the traditional model.

Does this mean that there is something in the idea of inspections itself that necessarily is hierarchical? Regardless of how one twists and turns, must inspections necessarily place the individual school in a context of dispassionate, rather bureaucratized analysis at the end of the day? Ehren and her colleagues do not draw this conclusion. Instead, they indicate that to capitalize on the potential of new networked form of polycentric governance, further work must be done on the political and legislative framing of school inspections to transform their current cultures of surveillance and control towards greater learning and experimentation. Only then will the promise of networked systems be supported, rather than constrained, by inspections.

The third article in this issue, entitled "School Leaders' Dilemmas and Measures to Instigate Change for Inclusive Education in Hong Kong" by Kim Fong PoonMcBrayer, likewise illustrates the ways that current school systems can constrain badly needed reforms. Poon-Brayer studied schools in Hong Kong that were considered exemplary for their leadership in facilitating special education services for their students. Her interviews revealed that principals and their staff were aware that they needed to comply with new ministerial ordinances promoting special education, while also worrying that accepting too many students with learning disabilities could result in parents withdrawing their children from their schools. This would have damaging consequences not only in terms of the reputations of 
their schools and their access to resources, but also could result in the closure of the schools if too many parents decided to send their children to other schools.

Poon-McBrayer shows that it was possible for principals to overcome these challenges by working carefully with their staff to develop their capacity for working with special needs students. Principals did this by coordinating their work carefully with special education needs coordinators and by serving as role models for teachers through their direct engagement with students with learning disabilities. Principals motivated teachers by appealing to their idealism to serve all students while also acknowledging the growing pains entailed in adapting instruction for new kinds of learners. As part of accelerating change, principals needed to exert a certain autocratic authority (the duty to comply with ministerial decrees requiring inclusive practices) along with an appropriate level of staff involvement (in making pedagogical and curricular adjustments). Significantly, $80 \%$ of the principals made the decision to accommodate special needs students without consulting their staff. In Hong Kong, school leaders are free to exercise authority without consulting staff, especially in regard to matters of equity and inclusion.

Such an unabashed exertion of power by principals can accelerate change by assuring that students with learning abilities will be supported from the government and by school leaders. Skeptics of inclusive policies will not be indulged. But what about situations where parents of marginalized students have less support from the system, and may have to face off not only against some teachers who are wary of change but also privileged parents who are eager to preserve their advantages? How can change be facilitated in those environments?

Jill Koyama and Fortidas Rwehumbiza Bakuza answer this question in their article entitled "A Timely Opportunity for Change: Increasing Refugee Parental Involvement in U.S. Schools." Their qualitative study of refugee parents in two schools in a declining northeastern city reveals that even in situations of material deprivation, public schools in the global North are more than capable of educating all of their students if they are able to accommodate new cultures of "spacemaking" and "identity-staking" for immigrant parents in their children's schools.

There are two challenges here. The first is that many educators are already accustomed to "place-taking" in the sense that they have established themselves as the sole authority in the classroom. The second is that many immigrant parents accept this role for the teachers, freely acknowledging their own lack of familiarity of U.S. schools.

These challenges were addressed in the two schools by capitalizing upon those educators and parents who saw new opportunities for cross-cultural learning in their schools. Some teachers saw the parents as allies. They made sure parents were always welcomed in their classes as guest speakers and translators. Some of the parents were considered professionals in their home countries, with degrees in engineering, for example, but conflict had driven them abroad. Such parents were well positioned to serve as math and science tutors. Change accelerated when such parents were fully brought into the school as resources for learning.

This hopeful account of the role of schools in welcoming refugees is complicated, however, in light of educators' own uncertainties about the telos of schooling. In the final article in this issue of the Journal of Educational Change, 
Kristy Drake addresses "Competing Purposes of Education: The Case of Underschooled Immigrant Students." Drake has studied the belief systems of educators in a California district with a large number of immigrant students. She found that they varied considerably based upon their roles in the system.

For teachers, students' ability to succeed in U.S. schools and society were dependent upon factors such as the ages of the students upon entrance to the country, their English language ability, and their level of prior education. District personnel, on the other hand, endorsed the official U.S. Department of Education emphasis upon college and career readiness. Lead teachers, counselors, and site administrators, for their part, were concerned primarily with the economic vulnerability of immigrant youth. Their goals were to help the youth to learn English as quickly as possible with an eye to acquiring marketable skills that would help them to survive in a competitive and often unforgiving economy.

Drake does not indicate which belief systems from the educators should be judged to be correct, but her research does indicate that for vulnerable youth, the slogan of college and career readiness may not be applicable. Psychologist of work David Blustein (2006) has documented that not just college, but also the idea of a career bears the hallmarks of middle-class mindsets that are predicated upon a certain level of economic security. Not just for underschooled immigrant youth, but also for the working class in general, jobs are not about careers, but about survival. Educators thus should not be surprised when their exhortations about college and career readiness fall on unreceptive audiences. It is not because college and careers might not be nice to imagine in the distant future, but that far more pressing survival issues are at stake.

The five articles in this issue indicate that the acceleration of change is a multifaceted and pervasive feature of education today. For the Journal of Educational Change, new topics crowd out older ones with astonishing frequency. In regard to school improvement strategies, educational systems evolve from monocentric to polycentric ones and their inspection systems struggle to keep up. Ministries demand inclusive special education policies and principals ensure that changes are brought about swiftly and thoroughly. Refugee parents arrive in new countries and develop new skill sets, creating new kinds of school cultures, in collaboration with their children's educators. Educators themselves struggle over the very purposes of schooling, understanding that while governments can advocate for higher standards and great aspirations, their students' lives may be much more grounded in the daily struggle to survive.

We thus need educators to be agile and conscientious in navigating change while holding onto the core values that brought us all into the profession in the first place. This can be done, but paradoxically only if there are enough interludes in the onslaught of change for deep, mindful reflection about the larger dynamics at work in our societies and how they impact the students in our schools (Shirley \& MacDonald 2016). To this degree, one proper response of the Journal of Educational Change to the age of acceleration is not to join in it and to go with the flow, but rather to slow it down. This is necessary so that we remember that there is no substitute for the existential imperative to treat each and every one of our 
students as ends in themselves, and not simply as grist for the larger economic machinery at work in our societies (Shirley 2017).

\section{References}

Blustein, D. (2006). The psychology of working: A new perspective for career development, counseling, and public policy. Mahwah: Lawrence Erlbaum.

Elmore, R. F. (1996). Getting to scale with good educational practice. Harvard Educational Review, $66(1), 1-27$.

Elmore, R. F. (2016). "Getting to scale..." it seemed like a good idea at the time. Journal of Educational Change, 17(4), 529-537.

Friedman, T. (2016). Thank you for being late: An optimist's guide to thriving in the age of accelerations. New York: Farrar, Strauss, \& Giroux.

McNeill, J. R., \& Engelke, P. (2014). The great acceleration: An environmental history of the anthropocene. Cambridge: Harvard University Press.

Shirley, D. (2017). The new imperatives of educational change: Achievement with integrity. New York: Routledge.

Shirley, D., \& MacDonald, E. (2016). The mindful teacher (2nd ed.). New York: Teachers College Press. 